\title{
MR Changes in the Calcarine Area Resulting from Retinal Degeneration
}

Mika Kitajima, Yukunori Korogi, Toshinori Hirai, Satoshi Hamatake, Ichiro Ikushima, Takeshi Sugahara, Yoshinori Shigematsu, Mutsumasa Takahashi, and Kazuo Mukuno

\begin{abstract}
PURPOSE: To study MR images for atrophic changes in the calcarine area resulting from retinal degeneration. METHODS: MR images from nine patients with retinal degeneration confirmed by ophthalmologic examination and from 30 healthy volunteers were reviewed. The causes of retinal degeneration were hereditary pigmentary degeneration of the retina (four patients), high myopia (two patients), and chorioretinal atrophy (three patients); all patients had visual disturbances and visual field abnormalities. To estimate the morphological changes of the calcarine area, the widths of the right and left calcarine fissures were measured on T1-weighted sagittal images and compared with images from age-matched control subjects. RESULTS: The calcarine fissures were significantly dilated in the patients with retinal degeneration. The anterior and middle points, which represent the peripheral visual field center, were more dilated than the posterior point. CONCLUSION: The MR findings suggested calcarine atrophy related to retinal degeneration. Transneuronal degenerative changes may occur in the calcarine area after retinal degeneration.
\end{abstract}

Index terms: Brain, magnetic resonance; Retina

AJNR Am J Neuroradiol 18:1291-1295, August 1997

The visual pathway from the retina to the striate cortex consists of three fibers. The first neuron contains a layer of bipolar and ganglion cells in the retina, the second neuron connects the ganglion cell layer and the lateral geniculate body, and the third neuron connects the lateral geniculate body and the striate cortex. Many earlier studies have shown that these neuroanatomic characteristics produce histologic changes in specific regions of the visual pathway, defined as transneuronal degeneration, caused by lesions of the retina and optic nerve $(1,2)$. Other studies have shown that distinct

Received September 4, 1996; accepted after revision February 21, 1997.

Presented at the annual meeting of the American Society of Neuroradiology, Seattle, Wash, June 1996.

From the Department of Radiology, Kumamoto (Japan) University School of Medicine (M.K., Y.K., T.H., S.H., I.I., T.S., Y.S., M.T.), and the Department of Orthoptics and Visual Science, Kitasato University School of Allied Health Science, Kanagawa, Japan (K.M.).

Address reprint requests to Mika Kitajima, MD, Department of Radiology, Kumamoto University School of Medicine, 1-1-1, Honjo, Kumamoto City, 860 Japan.

AJNR 18:1291-1295, Aug 1997 0195-6108/97/1807-1291

(C) American Society of Neuroradiology histologic changes in the visual cortex occur after removal of an eye, and that degeneration of the retina occurs after occipital ablation in animals $(3,4)$. Similarly, it is thought that histologic changes in the striate cortex appear as a consequence of retinal degeneration in humans. The purpose of this study was to evaluate the magnetic resonance (MR) imaging findings in the calcarine area resulting from retinal degeneration.

\section{Materials and Methods}

MR images were reviewed in nine patients (four women and five men; 52 to 80 years old; mean age, 69 years) with retinal degeneration confirmed by ophthalmologic examination and in 30 age-matched healthy volunteers (eight women and 22 men; 50 to 84 years old, mean age, 68 years). The causes of retinal degeneration were hereditary pigmentary degeneration of the retina (four patients), high myopia (two patients), and chorioretinal atrophy (three patients). All patients had visual disturbances and visual field abnormalities. One patient was examined on a 0.5-T superconductive MR unit, and the remaining eight patients and all the volunteers were studied on a 1.5-T unit. The sagittal T1-weighted MR images were obtained using a spin-echo sequence with imaging parameters of $450-$ 
TABLE 1: Calcarine fissure in patients with retinal degeneration

\begin{tabular}{|c|c|c|c|c|c|c|c|c|}
\hline \multirow{3}{*}{ Case } & \multirow{3}{*}{ Age, y/Sex } & \multirow{3}{*}{ Diagnosis } & \multicolumn{6}{|c|}{ Width of Calcarine Fissure, mm } \\
\hline & & & \multicolumn{3}{|c|}{ Right } & \multicolumn{3}{|c|}{ Left } \\
\hline & & & Anterior & Middle & Posterior & Anterior & Middle & Posterior \\
\hline 1 & $52 / \mathrm{F}$ & Pigmentary degeneration & 1.0 & 1.3 & 0.6 & 1.3 & 2.6 & 0.3 \\
\hline 2 & $57 / F$ & High myopia & 1.1 & 1.4 & 0.7 & 1.4 & 2.5 & 0.4 \\
\hline 3 & $62 / M$ & Pigmentary degeneration & 0.7 & 1.1 & 0.7 & 0.7 & 0.7 & 1.4 \\
\hline 4 & $69 / \mathrm{F}$ & Chorioretinal atrophy & 1.4 & 4.0 & 0.4 & 0.7 & 1.4 & 1.0 \\
\hline 5 & $71 / M$ & High myopia & 5.4 & 2.9 & 1.1 & 3.6 & 5.4 & 1.1 \\
\hline 6 & $73 / M$ & Chorioretinal degeneration & 3.6 & 1.1 & 0.4 & 3.6 & 1.8 & 1.8 \\
\hline 7 & $77 / M$ & Pigmentary degeneration & 1.8 & 3.6 & 1.1 & 3.6 & 1.1 & 0.7 \\
\hline 8 & $80 / M$ & Chorioretinal degeneration & 3.6 & 1.8 & 1.1 & 0.4 & 3.0 & 0.4 \\
\hline 9 & $80 / \mathrm{F}$ & Pigmentary degeneration & 1.0 & 1.4 & 1.3 & 4.0 & 5.0 & 2.5 \\
\hline
\end{tabular}

TABLE 2: Size $(m m \pm S D)$ of calcarine fissure in patients with retinal degeneration and in healthy volunteers

\begin{tabular}{lccccc}
\hline & \multicolumn{2}{c}{$\begin{array}{c}\text { Patients with } \\
\text { Retinal } \\
\text { Degeneration }\end{array}$} & $<70$ Years & $\geq 70$ Years & Total \\
\cline { 2 - 5 } & $2.16 \pm 1.53$ & $0.97 \pm 0.47$ & $0.93 \pm 0.35$ & $0.95 \pm 0.43$ & 0.0038 \\
Anterior & $2.33 \pm 1.40$ & $1.06 \pm 0.56$ & $1.10 \pm 0.36$ & $1.07 \pm 0.49$ & 0.0014 \\
Middle & $0.94 \pm 0.58$ & $1.08 \pm 0.44$ & $1.08 \pm 0.44$ & $1.08 \pm 0.44$ & 0.28 \\
Posterior & & & & \\
\hline
\end{tabular}

600/16-20/2-4 (repetition time/echo time/excitations). The section thickness was 5 to $6 \mathrm{~mm}$ with a 0.5 - to $1.0-\mathrm{mm}$ intersection gap. The field of view was 25 to 30 $\mathrm{cm}$, and the matrix size was $256 \times 256$. To estimate the morphological changes of the calcarine area, the widths of the right and left calcarine fissures were measured on T1-weighted sagittal images using a $\times 10$ magnifying glass with a $0.1-\mathrm{mm}$ scale, and sizes were compared between the volunteers and the patients with retinal degeneration. We compared the measurement scale on the magnifying glass with a standard scale printed on the film itself. The actual width of the calcarine fissure was obtained by calculating the reduced ratio on the film. The mean width at three points on the calcarine fissure-anterior, middle, and posterior-was calculated, and an unpaired $t$ test was used for statistical analysis.

\section{Results}

The width of the calcarine fissure varied from $0.3 \mathrm{~mm}$ to $5.4 \mathrm{~mm}$ in the patients with retinal degeneration (Table 1). The mean width was $2.16 \pm 1.53 \mathrm{~mm}$ (mean $\pm \mathrm{SD})$ at the anterior point, $2.33 \pm 1.40 \mathrm{~mm}$ at the middle point, and $0.94 \pm 0.58 \mathrm{~mm}$ at the posterior point (Table 2 ). The anterior and middle points of the calcarine fissure were more dilated than the middle point (Figs 1 and 2). In a 62-year-old patient (case 3 ) with pigmentary degeneration, atrophy was not observed at any point.

In the healthy volunteers, the mean width was
$0.95 \pm 0.43 \mathrm{~mm}$ at the anterior point, $1.07 \pm$ $0.49 \mathrm{~mm}$ at the middle point, and $1.08 \pm 0.44$ $\mathrm{mm}$ at the posterior point (Table 2). There was no significant difference in mean width among the three points of the calcarine fissure in any of the volunteers (Fig 3). The width of the calcarine fissure was nearly stable, even in elderly subjects, and there was no difference between the younger group $(<70$ years old) and the older group ( $\geq 70$ years old) (see Table 2 ).

The width of the calcarine fissure in the patient group was significantly larger than that in the control group at the anterior $(P=.0038)$ and middle $(P=.0014)$ points; however, at the posterior point, there was no statistically significant difference between the two groups $(P=.28)$.

\section{Discussion}

The retina consists of 10 layers. The retinal pigment epithelium occupies the most lateral layer of the retina, and the layer of rods and cones occupies the area medial to this. The rods and cones are important in the control of visual function. The cones control visual acuity and color vision and the rods control the light sense. The distribution and density of these two cells are different in the retina. The density is higher in the central region than in the peripheral re- 


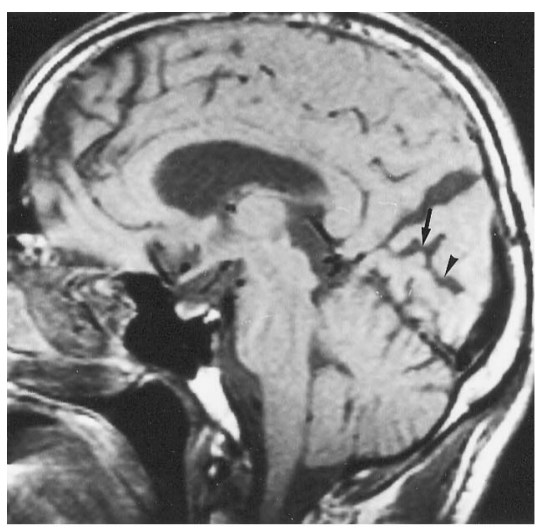

1

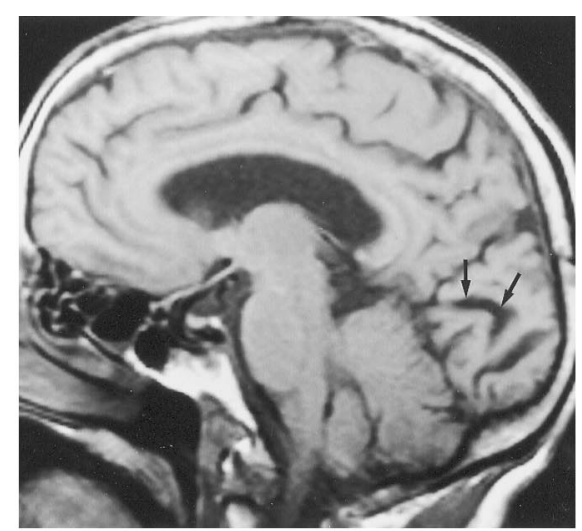

2

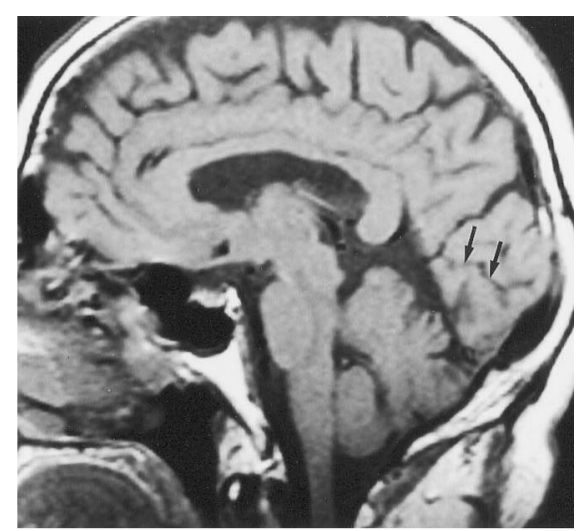

3

Fig 1. Case 5: 71-year-old man with high myopia. Sagittal T1-weighted image (600/20/2) shows marked dilatation of the calcarine fissure, in particular the anterior (arrow) and middle (arrowhead) points, each indicating a point at which a measurement was taken. (The posterior point is not shown in this section.)

Fig 2. Case 9: 80-year-old woman with pigmentary degeneration. Sagittal T1-weighted image (600/20/2) shows marked dilatation of the calcarine fissure, in particular the anterior and middle points (arrows).

Fig 3. A 70-year-old volunteer. Sagittal T1-weighted image (600/20/2) shows no dilatation of the calcarine fissure (arrows).

gion. The central region is occupied mainly by cones, the fovea consists of cones alone, and the peripheral region is occupied by rods (5).

The representation of the visual field in the occipital striate cortex was delineated by Inouye (6) and subsequently by Holmes and Lister (7) in studies of wounded soldiers in the RussoJapanese war and the First World War. Thereafter, Holmes devised his original "scheme," which gained widespread acceptance (8). In the Holmes retinotopic map, about $25 \%$ of the surface area of the striate cortex is allocated to the central $15^{\circ}$ of vision. The foveal representation is located at the occipital pole, where the striate cortex usually extends about $1 \mathrm{~cm}$ onto the lateral convexity of the occipital lobe. The extreme periphery of the visual field is represented anteriorly, at the junction of the calcarine and parietooccipital fissures.

Retinal degeneration and dystrophy include many pathologic conditions. The typical precipitating disease of primary retinal degeneration is hereditary pigmentary degeneration. It is a rare disease, with a frequency of approximately 1 in 3700 , and the heredity is $10 \%$ autosomal dominant, $84 \%$ autosomal recessive, and $6 \%$ $\mathrm{X}$-linked recessive. The characteristic symptoms are difficulty with dark adaptation and concentric contraction of the visual field (9). Retinal degenerative changes may be seen in a number of other disorders. It is well known that some hereditary metabolic and neurodegenerative diseases, such as mucolipidosis type 4 and olivopontocerebellar atrophy, cause retinal degeneration. High myopia and aging also cause secondary retinal degeneration. Pierro et al (10) evaluated the peripheral retinal changes associated with axial myopia and observed pigmentary degeneration, retinal hole, and retinal detachment in their patients with high myopia. Age-related macular degeneration and chorioretinal atrophy are generally seen after the age of 75 years (11). In these patients, neovascularity under the retina, which consists of local granulation tissue in the Bruch membrane, is observed at histologic examination (12).

One of the neuroanatomic characteristics of the visual pathway is transneuronal degeneration. It occurs in neurons when fibers afferent to them are lost (13), and is common in the lateral geniculate body after loss of an eye or in association with lesions of the retina, optic nerve, or optic tract. Several histologic studies have shown that transneuronal changes might also occur in the visual cortex in the presence of lesions of the lateral geniculate body or after eye removal, especially in young animals (14). Globus et al (15) found a statistically significant loss of dendritic spines on the apical dendrites of certain pyramidal cells in the visual cortex after eye enucleation in rabbits and mice. These earlier investigators claimed that it was difficult 
to distinguish transneuronal degeneration from disuse, and that electromicroscopic findings were necessary to discriminate between them.

In our study, the width of the calcarine fissure was dilated more in patients with retinal degeneration than in healthy volunteers. In particular, the anterior and middle points were more severely disturbed. However, one third of the patients had some measurements that were within the range of normal (Table 2). The causes of this variability are unknown. Since the duration of the disease process is long (more than 10 years in almost all patients), there seems not to be a correlation between the duration of disease and the degree of atrophy in the calcarine area. In addition, there was no difference in degree of atrophy among the types of diseases. Histologic examinations were not performed in our study, but the transneuronal degeneration we found in the striate cortex might have resulted from retinal degeneration. Aging did not appear to be the cause of atrophy of the anterior and middle points, since the width of the calcarine fissure was nearly stable, even in the elderly patients. However, as retinal degeneration in people older than 75 years occurs mainly in the macular region, whose visual field projects onto the most posterior of the calcarine area, the sagittal MR images may not have depicted any atrophic changes.

It is known that the rods and retinal pigmentary epithelia degenerate in patients with hereditary pigmentary degeneration (9). Considering the distribution of the rods in the retina, it was expected that the atrophy of the striate cortex was more severe at the anterior points in patients with pigmentary degeneration. However, even in other cases of retinal degeneration, the distribution of atrophy in the calcarine area was similar. The mechanism of this vulnerability of the anterior half of the striate cortex has not been clarified. The lower cell density in the peripheral retina may be related to the relatively selective involvement of the anterior portion of the calcarine area. When a retinal lesion occurs, the peripheral visual field may be more disturbed.

In recent years, $M R$ imaging has become an important diagnostic tool for the demonstration of fine anatomic structures and pathologic changes in the brain. It clearly depicts the unique distribution of calcarine involvement in various disorders. Involvement of the bilateral occipital striate cortex is observed in patients with infarction associated with arteriosclerosis of the posterior and/or middle cerebral arteries, bilateral tentorial herniation subsequent to severe head trauma, generalized hypoxia, or specific organic matter (16-18). For example, in patients with organic mercury poisoning ( $\mathrm{Mi}$ namata disease), MR images depict significant dilatation of the ventral portion of the calcarine sulcus and long $\mathrm{T} 1$ and $\mathrm{T} 2$ relaxation times within the striate cortex, which might represent status spongiosus (18). This finding is very similar to our findings, although the causes of involvement of the bilateral occipital striate cortex in our cases were different from these conditions. Atrophy of the striate cortex in patients with retinal degeneration is thought to be a consequence of the retinal degeneration.

Because our study was limited by the absence of histologic data, it is difficult to attribute atrophy of the calcarine area to transneuronal degeneration. However, when associated with lesions of the retina, atrophy of the calcarine area may be the result of transneuronal degeneration.

\section{Conclusion}

Our MR findings suggest calcarine atrophy is a consequence of retinal degeneration. In particular, the atrophy was more severe at the anterior and middle points of the calcarine area, suggesting that transneuronal degenerative changes can occur in the calcarine area after retinal degeneration. This pathologic change should be distinguished from disorders involving primarily the occipital striate area.

\section{References}

1. Haddock JM, Berlin L. Transsynaptic degeneration in the visual system. Arch Neurol Psychiatry 1950;64:66-73

2. Kuper $C$. The distribution of cell size in the lateral geniculate nucleus of man following transneuronal cell atrophy. $J$ Neuropathol Exp Neurol 1965;24:645-661

3. Van Buren JM. Trans-synaptic retrograde degeneration in the visual system of primates. J Neurol Neurosurg Psychiatry 1963; 26:402-409

4. Cowan WH. Antegrade and retrograde transneuronal degeneration in the central and peripheral nervous system. In: Nauta WHJ, Ebbesson SOE, eds. Contemporary Research Methods in Neuroanatomy. New York, NY: Springer; 1970:217-251

5. Kölmel HW. Die homonymen Hemianopsien: Klinik und athophysiologie zentraler Sehstorungen. 3rd ed. Berlin, Germany: Springer; 1990:1-10

6. Inouye T. Die Sehstorungen bei Schussverletzengen der kortikalen Sehsphare. Leipzig, Germany: Engelmann; 1909 
7. Holmes G, Lister WT. Disturbances of vision from cerebral lesions with special reference to the cortical representation of the macula. Brain 1916;39:34-73

8. Holmes G. The organization of the visual cortex in man. Proc R Soc Lond B Biol Sci 1945;132:348-361

9. Lessel S, Lessel IM, Glaser JS. Hereditary pigmentary degeneration of the retina. In: Tasman W, Jaeger EA, eds. Clinical Ophthalmology. Rev ed. Philadelphia, Pa: Lippincott; 1991:1-28

10. Pierro L, Camesasca FI, Mischi M, Brancato R. Peripheral retinal changes and axial myopia. Retina 1992;12:12-17

11. Klein R, Klein BE, Linton KL. Prevalence of age-related maculopathy, the Beaver Dam Eye Study. Ophthalmology 1992;99: 933-943

12. Grossklaus HE, Martinez JA, Broron VB. Immunohistochemical and histochemical properties of surgically excised subretinal neovascular membranes in age-related macular degeneration. Am J Ophthalmol 1992;114:464-472
13. Duchen LW. General pathology of neurons and neuroglia. In: Greenfield H, Corsellis JAN, Duchen LW, eds. Neuropathology. 4th ed. New York, NY: Wiley; 1984:18-19

14. Van Buren JM. Trans-synaptic retrograde degeneration in the visual system of primates. J Neurol Neurosurg Psychiatry 1963; 26:402-409

15. Globus A, Scheibel AB. Loss of dendrite spines as an index of pre-synaptic terminal patterns. Nature 1966;212:463-465

16. Kölmel HW. Die homonymen Hemianopsien: Klinik und athophysiologie zentraler Sehstorungen. 3rd ed. Berlin, Germany: Springer; 1990:42-49

17. Tanaka R, Miyasaka Y, Yada K, Mukuno K. Bilateral homonymous hemianopsia due to tentorial herniation, with sparing of central vision: case report. Neurosurgery 1992;31:787-791

18. Korogi Y, Takahashi M, Shinzato J, Okajima T. MR findings among seven patients with organic mercury poisoning: Minamata disease. AJNR Am J Neuroradiol 1994;15:1575-1578 